Article

\title{
Showing/Sharing: Analysing Visual Communication from a Praxeological Perspective
}

\author{
Maria Schreiber \\ Department of Sociology, University of Vienna, 1090 Vienna, Austria; E-Mail: maria.schreiber@univie.ac.at
}

Submitted: 23 June 2017 | Accepted: 13 November 2017 | Published: 21 December 2017

\begin{abstract}
This contribution proposes a methodological framework for empirical research into visual practices on social media. The framework identifies practices, pictures and platforms as relevant dimensions of analysis. It is mainly developed within, and is compatible with qualitative, interpretive approaches which focus on visual communication as part of everyday personal communicative practices. Two screenshots from Instagram and Facebook are introduced as empirical examples to investigate collaborative practices of meaning-making relating to pictures on social media. While social media seems to augment reflexive, processual practices of negotiating identities, visual media, in particular, amps up aesthetic, ambivalent and embodied dimensions within these practices.
\end{abstract}

\section{Keywords}

Facebook; iconography/iconology; Instagram; Internet research; media practices; practice theory; qualitative research; social media; visual communication; visual methods

\section{Issue}

This article is part of the issue "Visual Communication in the Age of Social Media: Conceptual, Theoretical and Methodological Challenges", edited by Uta Russmann (FHWien der WKW University of Applied Sciences for Management \& Communication, Austria) and Jakob Svensson (Malmö University, Sweden).

(C) 2017 by the author; licensee Cogitatio (Lisbon, Portugal). This article is licensed under a Creative Commons Attribution 4.0 International License (CC BY).

\section{Introduction}

Visual communication on social media is on the risewith networked, ubiquitous cameras on devices like smartphones, communicating in and through pictures and especially photos became a common everyday practice (Hand, 2012; Highfield \& Leaver, 2016; Lehmuskallio \& Gómez-Cruz, 2016). In 2016 for example, 400M photos have been uploaded on Facebook, compared to $250 \mathrm{M}$ in 2013 , and 760M were shared on Snapchat. ${ }^{1}$ While enormous amounts of pictures are shared through a broad variety of apps every day, the crucial question for qualitative research is how these sharing practices become relevant in specific contexts and lifeworlds. Communication on social media is made up of a complex array of visual, textual, aural and other articulations, within specific soft- ware environments. While quantitative approaches or automated analyses of digital communication data tend to grasp traces of what users do online, ${ }^{2}$ qualitative approaches are interested in why and how they do it.

The research described in this contribution was guided and framed by the following research question: How does collaborative meaning-making of visual media take place on social media platforms? Recent research has shown that performing and constituting identities online is strongly socially entangled (Marwick, 2013; J.-H. Schmidt, 2013), iterative, productive and interpellated (Thiel-Stern, 2012). While identities have always been constituted socially and collaboratively (Bourdieu, 1972; Goffman, 1959), the ways, how, and where these practices take place have transformed: social realities are increasingly constructed and organized within specific net-

\footnotetext{
1 https://cewe-photoworld.com/how-big-is-snapchat

2 For more detailed accounts on the possibilities and constraints of big data in digital research and automated analyses of platform content see (boyd \& Crawford, 2012; Mahrt \& Scharkow, 2013)
} 
worked media logics (Klinger \& Svensson, 2015), which emerge in individualized, networked and prod-used content and practices (Klinger \& Svensson, 2015). Practices of social identity-making have become potentially more reflexive through their visibility and mediation in and on social media (Leaning, 2009; Marwick \& boyd, 2011). Therefore, it is fundamental to conceptually and methodologically take into account the visual and material character of practices of identity/sociality-making when researching visual social media (Lehmuskallio \& GómezCruz, 2016).

Couldry and Van Dijck (2015) deem empirical work "that tracks in everyday life the mechanisms by which today's space of social appearances is being built, its entry and exit points, and rules of operation" as particularly important-yet we have to continuously develop, question and adapt the methods and methodologies we use to carry out our empirical work. Therefore, this article outlines and applies a flexible framework for qualitative, interpretive research on visual communication in social media which is based on a praxeological approach (Bourdieu et al., 1990; Burri, 2012; Reckwitz, 2002). Strategies of interpretation of multimodal material such as screenshots are introduced, which take into account the respective logics and (visual) modalities of the available data.

First, I briefly situate the framework within qualitative internet research (2), then theoretical implications and conceptual prerequisites are discussed before (3) the framework as a link between theory and empirical research is introduced. (4) The framework is then empirically applied in an in-depth analysis of two screenshots, followed by (5) a comparative analysis which lead up to (6) conclusions regarding the research questions and the applicability of the framework in general.

\section{A Qualitative Approach to Internet Studies and Digital Data}

Qualitative research contextualizes, interrogates and compares data and is interested in how meaning is constituted and negotiated in specific contexts (Markham, 2012, 2013; Schirmer, Sander, \& Wenninger, 2015). Digital data, therefore, is both a blessing and a curse for qualitative research: self-expression and interaction become bit-based data-objects, which can be easily stored and analysed. Within an interpretive paradigm, it is crucial to understand how a piece of data is relevant in the lifeworld of a participant and what it actually represents or constitutes within this context-yet this challenge is hardly new or specific to digital data. The strengths of qualitative internet studies as elaborated by Baym (Baym, 2009, p. 179) can, therefore, be understood as quality criteria of qualitative research in general and also for the framework, which will be developed:

- grounded in theory and data;

- demonstrates rigour in data collection and analysis;

- uses multiple strategies to obtain data;
- takes into account the perspective of the participant;

- demonstrates awareness of and self-reflexivity regarding the research process;

- takes into consideration interconnections between the internet and the life-world within which it is situated.

As general complexities and challenges of "internet research" are discussed in more detail elsewhere (Ardèvol \& Gómez-Cruz, 2013; Hine, 2015; Markham, 2004; Markham \& Baym, 2009; Pink et al., 2015), this contribution will focus on the question of how to specifically deal with visual data in social media contexts from a qualitative perspective.

While research on visual social media has recently become more prominent in many disciplines (see Russmann \& Jakob, 2017), theories, methods and methodologies rarely relate to previous theoretical or methodical scholarship on visuality, as Rose (Rose, 2014, p. 41) points out. Research on the specifics of visual social media lags behind that of text-based media, as Highfield \& Leaver (2016) point out in a "rallying cry and provocation for further research into visual (and textual and mixed) social media content, practices, and cultures, mindful of both the specificities of each form, but also, and importantly, the ongoing dialogues and interrelations between them as communication forms" (Highfield \& Leaver, 2016, p. 47). The speed and diversity of recent innovations and developments in visual online communication (such as Memes, Vines, GIFs, Stories, augmented reality visualisations etc.) might certainly feel overwhelming and conceptually confusing to researchers. This contribution aims to outline a theoretically informed and empirically tested framework for analysing visual data embedded in social media from a praxeological perspective.

A crucial methodological prerequisite is that the analysis of a visual itself cannot show or explain how a visual element is relevant in an actor's life world or how it is perceived by other users. However, visual data analysis can unearth aesthetic, embodied and affective aspects of communicative relations which might otherwise be overlooked (Grace, 2014; Przyborski, 2017; Rose, 2012; Tinkler, 2013). To understand the complex entanglements of visual and social media, both their "media logics" have to be taken into account method(olog)ically. I, therefore, propose a triangulation of methods as fundamental; this implies that three conceptual aspects-practices, pictures and platforms-are objects of investigation of three methods-visual analysis, text analysis and platform analysis.

As mentioned previously, visual analysis has to be combined with additional data, such as interviews or ethnographic accounts to analyse the relevance, meaning and communicative context of visual elements. Moreover, taking into account recent theoretical scholarship (Burri, 2012; Lehmuskallio \& Gómez-Cruz, 2016; Schade \& Wenk, 2011), the framework advocates and empha- 
sizes the importance of visuality and materiality of any picture practice. In her "Sociology of Images", Burri (2012) points out that the triad of practice, materiality, and visuality has to be conceptually entangled to understand pictures and pictorial practices in their epistemic, material and social multiplicity. Lehmuskallio \& GómezCruz (2016, p. 5) also propose to understand visual communicative practices as being "both part of social symbolization processes and materially mediated". While this is usually not contested on a theoretical level, visuality and materiality are rarely accounted for in concrete research methods. The integration of the respective specifics is therefore critical to the proposed framework. The conceptual implications of the framework will now be introduced in more detail.

\section{Theoretical Implications of the Proposed Framework}

Visual communication on social media is conceptualized as a digitally mediated communicative practice which leaves traces: "Both self-expressions and interactions between people produce bit-based content in networked publics" (boyd, 2011, p. 46). As pointed out above, the challenges of interpreting visual bits of data are twofold: Researchers have to understand the particularities of pictures as symbolic, visual media which are embedded in communicative practices, and they have to take into account social media platforms, which are understood as active participants with specific possibilities and constraints.

These three layers-practices, pictures and platforms-are therefore rendered as the three conceptually important objects of investigation, data collection and interpretation in the proposed framework. While "in action" these layers are of course always entangled and enmeshed, they will be dissected for analytical purposes. First, the theoretical implications of a practice approach (3.1) which takes into account visuality (3.2) and materiality (3.3) as constitutive will be briefly outlined. Then, concrete steps of analysis and interpretation will be introduced (3.4). An exemplary analysis will be conducted along two concrete empirical examples of stepby-step interpretations of screenshots from Instagram and Facebook (4).

\subsection{Practices}

The proposed framework is based on a praxeological understanding of media use, which focuses on everyday media practices and their entanglement with lifeworlds. Praxeological approaches imply a social-constructivist, cultural theoretical perspective on media practices. They focus on actors and their habitualised doings and sayings (Bräuchler \& Postill, 2010; Couldry, 2004) mostly on a micro-level, but understand these as linked to social structures: practices are understood to be structured by implicit, incorporated knowledge and habits which are shared collectively (Bourdieu, 1972; Mannheim, 1998).
Praxeological approaches aim to understand underlying cultural orientations and routines which make seemingly mundane and predictable practices so mundane and predictable (Hörnig \& Reuter, 2004, p. 13).

Meaning and identities are understood as collaboratively produced-and continuously reproduced-in communicative interactions (Goffman, 1959; Mead, 1967). While the collaborative negotiation of meanings is not new perse, recent research shows that digital, networked media may allow practices of negotiation to be quicker, more public and also potentially more reflexive and conscious (Leaning, 2009; Marwick, 2013; Marwick \& boyd, 2011) - they are, so to say, "amped up by immediacy and hyper-social nature of digital media today" (Thiel-Stern, 2012 , p. 100). Leaning also argues that "The internet brings particular social processes "closer" to the user and increases the individual's experience of them-it plays a considerable part in making us late-modern" (Leaning, 2009, pp. 158f.). These findings are also related to an increased attention towards potential media logics (Klinger \& Svensson, 2015) or affordances (Hutchby, 2001) which are co-constituting practices of communication-as will be briefly mapped out in section 3.3.

Our hypersociality and accompanying increased sensitivity of how users communicate with specific (imagined) audiences in specific contexts has been emphasized in recent research (Abidin, 2016; Marwick \& boyd, 2011; Van Dijck, 2013b). The increasing importance of visual media in digital communication seems unquestioned, yet we rarely take a closer look at how visual communication is actually practised on a micro-level in decentralized, interpersonal communication on social media. How do users "audience" pictures? Do visual media allow for differentiated tonalities, cultural markers and insider jokes? How can we grasp visual media method(olog)ically?

\subsection{Pictures}

Pictures which are shown and shared on social media can be conceptualised firstly as a visual expression and a record of the habitus of the individual who shared the picture (Bohnsack, 2008; Goffman, 1987). What Bourdieu states in his 1960s study on personal photography, holds true for the sharing of pictures on social media: "the most trivial photograph expresses, apart from the explicit intentions of the photographer, the system of schemes of perception, thought and appreciation common to a whole group" (Bourdieu et al., 1990, p. 6). Secondly, one authenticates a specific picture as being relevant through its being shared on an account on a specific platform with a specific audience and the picture then becomes a site of visual communication between at least two users.

Pictures and especially personal photos depict and display taste, aesthetics and embodied performances (Goffman, 1987; Müller, 2011) as well as sensory, atmospheric and affective elements (Degen, Melhuish, \& 
Rose, 2017; Grace, 2014; Hjorth \& Lim, 2012). With Goffman, pictures can be understood as condensed performances of practices that otherwise might be fleeting and hard to grasp/collect: "The rendition of structurally important social arrangements and ultimate beliefs which ceremony fleetingly provides the senses, still photography can further condense" (Goffman, 1987, p. 10), therefore "pictorial artifacts allow for a combination of ritual and relic" (Goffman, 1987)-like all bit-based data, digital pictures shared on social media are documents and elements of interactions, performances, and rituals. The analysis of pictures specifically aims to reconstruct the meaning conveyed visually and aesthetically, for example, through composition, perspective, scenic choreography, colours, contrast etc. The logics of visual media have to be taken into account-just as discursive and linguistic logics, and standards of communication are taken into account when analysing text (Przyborski \& Slunecko, 2012).

Yet a single picture can only show a specific aspect of a habitus or lifeworld, namely the part of the self that has been allowed to be shown and shared on that specific platform with that specific audience, in that specific context, at that specific time. Moreover, the interpretation of a single picture may find multiple and ambiguous layers of meaning which exist in parallel (Imdahl, 1994; Przyborski, 2017), ${ }^{3}$ as we will see in the exemplary interpretations. Sharing pictures on social media can have manifold meanings and contexts, and has to be understood as a field full of continuities and changes: Picture sharing has always been a means of collaborative meaning-making and "doing sociality" (Keightley \& Pickering, 2014; Sarvas \& Frohlich, 2011) yet through social media modes of individual sharing have become more common than sharing within the family. Moreover, pictures may become conversational, ephemeral communicative elements (Van Dijck, 2007; Villi, 2015) especially in applications such as WhatsApp or Snapchat.

Therefore, understanding how sharing practices are entangled with social lifeworlds and technical affordances means on the one hand, to think big-by adding additional data with interviews and/or ethnographic for a holistic understanding of the context and lifeworld; and on the other hand, to think small-by going in depth; analysing what is already there, and exploring the entanglements that are inscribed in small pieces of data. Therefore, close readings and fine-grained analyses of multimodal data can be revealing and helpful to understand how we communicate visually online.

If we understand shared pictures as elements of communication, the underlying method(olog)ical questions are first: how exactly does this communication take place, and secondly, how does the media environment where a picture is shared become relevant? While visual communication has always been mediated, from cave paintings to polaroids, the entanglement of (visual) practices with hardware and software has increased the complexity of the mediation. Therefore the next section will take a brief look at the relevance of platform defaults and interfaces.

\subsection{Platforms}

In Media and Communication Studies the awareness of algorithm, code, and software as being constitutive elements of media practices has increased in recent years (Bucher \& Helmond, in press; Gillespie, 2013; Hutchby, 2014), in line with a broader "new materialism" in social and cultural research (Barad, 2003; Brown, 2010; Latour, 1991). How does a digital, networked media environment and its social media logic (Van Dijck \& Poell, 2013) or networked media logic (Klinger \& Svensson, 2015) affect media practices, communities, economies and societies? How can the material and technical structures we act upon and interact with be conceptually and empirically integrated (Latour, 1991; Zillien, 2008)? ${ }^{4}$ Researchers try to overcome techno-deterministic understandings of media practices (Hutchby, 2001; Klinger \& Svensson, 2015) yet there is no common ground regarding exactly how technical features and characteristics should be theoretically and empirically integrated; furthermore methodical approaches are scarce-with some exceptions (Light, Burgess, \& Duguay, 2016; McVeighSchultz \& Baym, 2015).

For the framework, which is interested in visual communicative practices on a small-scale micro level, I propose to follow these approaches and to integrate material specifics of platforms in the analysis. An analysis of affordances of apps or platforms can carve out the "material substratum which underpins the very possibility of different courses of action in relation to an artefact" (Hutchby, 2001, p. 450). While affordances are defined not as being deterministic or relativistic, but as relational (Hutchby, 2001), underlying patterns of how platforms connect, moderate, select etc. might be analytically reconstructed. Affordances become visible for the researcher mainly through the interface but also through default settings (Van Dijck, 2013a).

Therefore, an analysis of these elements, defaults and interfaces of platforms will be conducted as the third element of the framework, following approaches such as that of Light et al. (2016) and McVeigh-Schultz \& Baym (2015); again there will be two steps of analysis: description (what?) and interpretation (how?).

\section{Introducing the Framework}

Building on the theoretical concepts and method(olog)ical arguments that have been introduced in the previous

\footnotetext{
${ }^{3}$ The conceptual idea of multiple layers of meaning which exist at the same time, but are activated in different ways by different audiences, goes beyond Hall's idea of transformation of meaning, as elaborated by Przyborski (2017, p. 76).

${ }^{4}$ Praxeological approaches as well have always understood both (human) bodies and (non-human) things as active participants in social practices (Hörnig \& Reuter, 2004; Latour, 1991; Reckwitz, 2002; R. Schmidt, 2012).
} 
two sections, this section outlines a framework for analysing visual communication on social media from a praxeological perspective.

It was originally developed within the logic of the Documentary Method, a qualitative, praxeological approach (Bohnsack, 2008, 2014; Przyborski, 2017), but it is compatible with any kind of qualitative, interpretive approach which differentiates two levels of meaning (explicit and implicit meaning) and relates them in a systematic manner: What is said or visible is separated from how this content is actually conveyed within language (e.g. transcripts of interviews), practice (e.g. observation notes), or pictures (e.g. screenshots). Through reconstructing the how, the documentary method aims to reconstruct habitual, implicit patterns of practice, which are understood as a tacit knowledge, embedded in everyday practices of action and perception (Bourdieu, 1972). These two steps of analysis (what? \& how?) are conducted on each of the three levels - practices, pictures and platforms.

This approach enables the analysis of patterns and habits that go beyond intentional, instrumental-rational action without claiming any a-priori-knowledge of these structures. The in-depth analysis aims to understand habitual patterns of picture sharing and sense-making within networked media environments. Through close reading and analysis of the collected material, implicit patterns can be reconstructed.

Figure 1 gives an overview of the conceptual idea of the framework: Visual communication on and in social media are practices with pictures on platforms. While of course all three elements are entangled in practice (Barad, 2003, 2007), they are analytically dissected to uncover the respective characteristics of the available data.
- Practices are the underlying methodological concept and the main object of research-they are analysed through interviews, ethnographic accounts but also through comments which refer to the pictures shared on social media.

- These pictures are understood as visual expressions and documents of habitus, as well as elements of communication practices. While screenshots, in a broader sense, are pictures, they also contain multimodal data that allows us to analyse not just practices of collaborative-meaning making but also the platforms themselves.

- The platforms' interfaces, defaults and affordances can be accessed through screenshots and walk-throughs (Light et al., 2016) but the analysis can also be extended to economic, algorithmic and other factors.

The framework proposes the analysis of these three layers as a flexible and adaptable research strategy (Hine, 2015; Hirschauer, 2008; Markham, 2013), not as a standardized model or process. Therefore the order and emphasis should, of course, be systematically adapted and related to the research question. The framework pushes forward an analytical dissection of the three layers as the first step. However, following this, it is crucial to relate the findings back to each other and to analyse how these layers constitute, push, and facilitate each other-or not, as the case may be. As the final step, a comparative analysis with other practices, pictures and/or platforms is highly recommended to carve out and situate the respective specificities, similarities and differences. Concepts of media environment or polymedia can be particularly

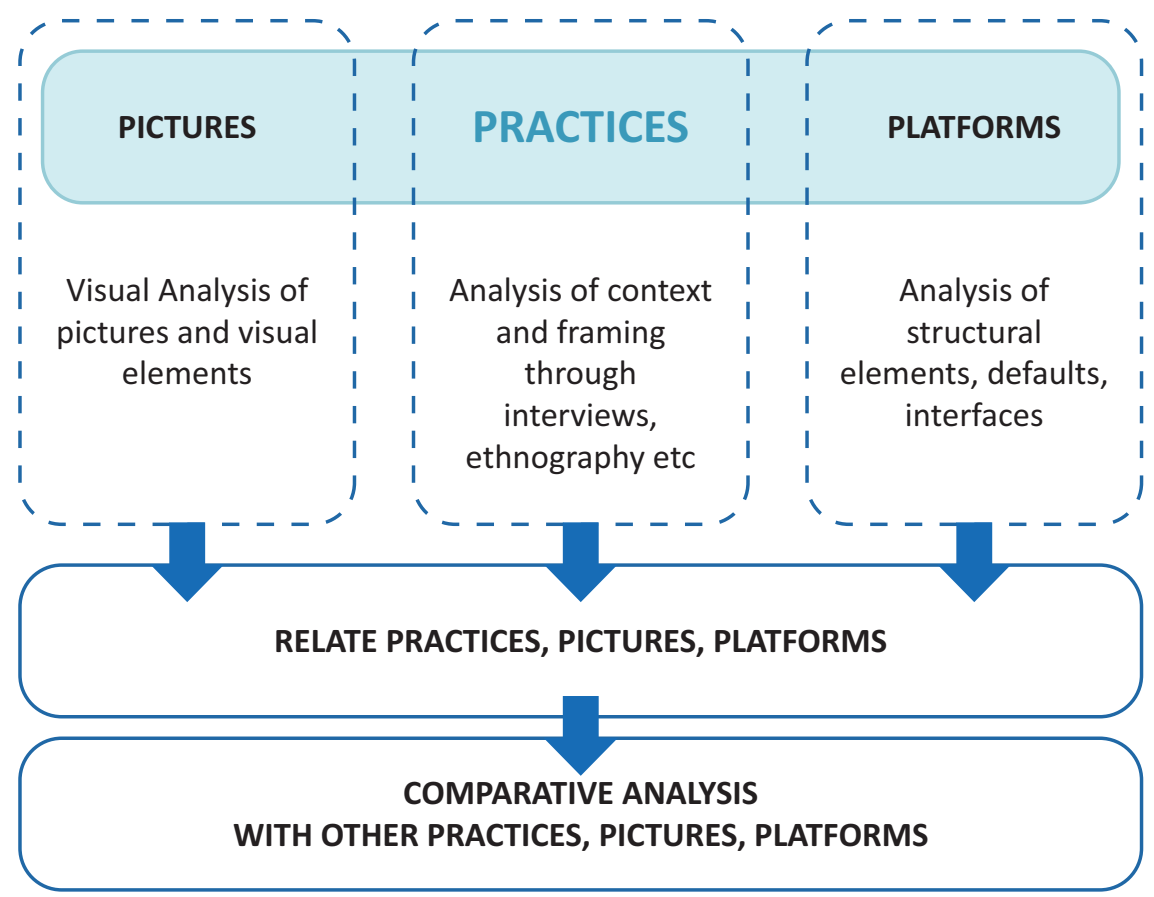

Figure 1. Framework for analysing visual communication on social media. 
helpful and inspiring at this stage (Gershon, 2010; Hasebrink \& Hepp, 2017; Madianou \& Miller, 2012).

Regarding the examples in this article, collection, interpretation and analysis are led by the research question outlined in the introduction: How does collaborative meaning-making of visual media take place on social media platforms?

\subsection{Data Collection, Interpretation and Comparative Analysis}

For this contribution, screenshots are introduced as a simple form of data collection to understand collaborative meaning-making practices in social media contexts. Screenshots not only include the shared picture but also the corresponding framing through the inclusion of captions, likes, comments, and moreover, they clearly show the interface within which the picture was shared. Screenshots contain and show communicative practices and therefore give access to a detailed understanding of mediated and multimodal communication. They can be ideal starting points or support data to understand visual communication on social media. However, as already pointed out above, they should always be supported by additional data. Like most qualitative data, a screenshot is a snapshot of a specific time and event; to understand change and continuities in visual practices, additional data or longitudinal studies of practices via screenshots are needed-depending on the research aim and question. Yet the framework is not only suitable for the analysis of screenshots, but any form of multimodal data collected online which is interested in visual communication in or on social media. In any case, informed consent and ethical agreement with the participants about the use of all data is critical (Markham \& Buchanan, 2015).

The exemplary interpretations will start with a visual analysis of the picture, following an iconographic- iconologic approach (Bohnsack, 2008): the pictures were first described (iconographically) and then interpreted (iconologically), yet in the examples below these two steps are already condensed. Based on screenshots, the communicative elements which directly refer to the picture are identified and interpreted as discursive practices of collaborative meaning-making (Thiel-Stern, 2012). Finally, the default settings and interface structure (McVeigh-Schultz \& Baym, 2015; Van Dijck, 2013a) of the respective platforms where the pictures were shared was also taken into account as constitutive elements which co-constitute practice and picture.

The interpretations of the three elements are then related to each other. Finally, it is possible to perform a comparative analysis with other pictorial practices such as those of other users on the same platform, or other pictures of the same user on another platform, etc.

\section{Applying the Framework: Empirical Examples}

The data of both participants was collected and analysed in my dissertation project (Schreiber, in press) and the screenshot of Anna has also previously been discussed (Schreiber \& Kramer, 2016). All names and faces were anonymized and/or pixelated.

\subsection{Example "Anna"}

I first interviewed Anna in early 2014 together with a friend of hers, she allowed me to follow her on Instagram and I saved this picture plus comments as it was the most recent picture that Anna had posted of herself at the time of the first interview. When I interviewed them again about one year later, she had already deleted it.

In the greytone picture of Figure 2, 13-year-old Anna is positioned in front of a light, greyish background and looks at the camera, respectively - the viewer. Her face and her torso are visible from the sternum upwards. Her
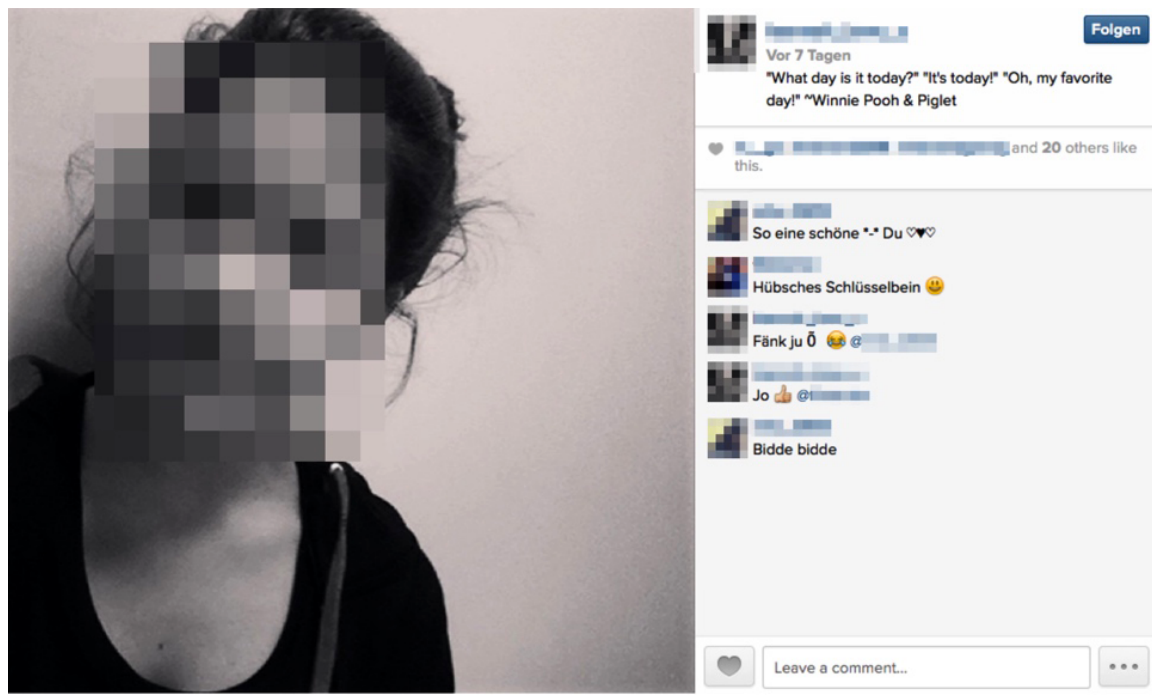

Figure 2. Screenshot from Instagram browser view. 
hair is loosely held together on the back of her head, some strands of hair are loose, her lips are closed, her eyes open. Her head is slightly tilted to the right. She wears dark clothes, a top with a U-shaped neckline with the lowest point of the neckline on her sternum, where a conic shadow is visible. The neckline also touches the lower frame of the picture. The loose hair stresses a sporty, relaxed hairstyle which is underlined by the hoodie she is wearing. Yet the U-shaped, feminine and quite low neckline of the top she wears below the hoodie refers to a more grown-up, feminine style. The darkest parts of the picture, shirt and hoodie, frame on the one hand the inner contour of her body, the neckline and skin, and on the other hand the outer contour, her head and shoulders against the diffuse background.

Taking a look at the compositional structure of the picture (Figure 3), the girl takes up two-thirds of the picture while one third on the right remains empty. The figure seems to rise into the frame in a lopsided/tilted way from the left. Format, framing and central perspective highlight the tilt of her head and the frontal, direct gaze. It is not really a close-up (just the top of her forehead is not visible), yet not really a classic Renaissancestyle portrait frame. Iconographically, the portrait seems to contain multiple or even contrary meanings also on other levels: her clothing is sporty yet feminine, we see a body in-between stages of development, namely a rather gender-neutral childhood and a gender binary female adolescence.

Anna's username is "Anna_love_u", an English phrase which basically is an expression of (not necessarily romantic) love towards an undefined Instagram audience " $u$ ", whoever sees this. Yet a grammatically correct sentence would be loveS. It seems that "love" here is a substitute for a heart-symbol, which is often used instead of the written "love", yet symbols cannot be part of Instagram usernames. The caption Anna added is an English quote from a popular meme or inspirational quote: "What day is it today?" "It's today" "Oh that's my favourite day", from Winnie Pooh \& Piglet.
By using this quote as a caption for her picture, Anna authorises the meaning of the quote as an important framing element for the picture. It conveys a state of mind that refuses a time or calendar scheme as structurally important and also shows enthusiasm for living in the moment. The quote and the named protagonists refer to an infantile lifeworld and developmental stage, where anthropomorphic creatures wander around and speak. As a child, a different structure of weekdays and time-schedules are more relevant than for a grown-up professional life and "living in the moment" is possible in a different way.

Both commentators (see Table 1 ) refer to Anna's looks or appearance:

Table 1. English translation of German comments which are visible in Figure 2.

\begin{tabular}{l} 
C1: Such a beauty *_* You \\
C2: Pretty collarbone :-) \\
\hline A: Thank you (lachsmiley) @C1 \\
\hline A: Yo (y) @C2 \\
\hline C1: Welcome welcome
\end{tabular}

While a comment on Instagram is not necessarily embedded in a reciprocal, conversational structure and followed by a reply or another comment, Annas replies to the comments about her picture, she thanks the commentators for the comments and addresses the comments directly to them by using the @username link (this default structure is further discussed in section 3.3). Anna's thanks and replies are framed by a rather ironic or trivializing tone.

The caption emphasizes and stresses the timelessness and placelessness that the picture already hints at. Posture, background and clothing do not point to a specific place or event, the figure seems rather ambiguous and in-between. Anna frames the diffuse visual element
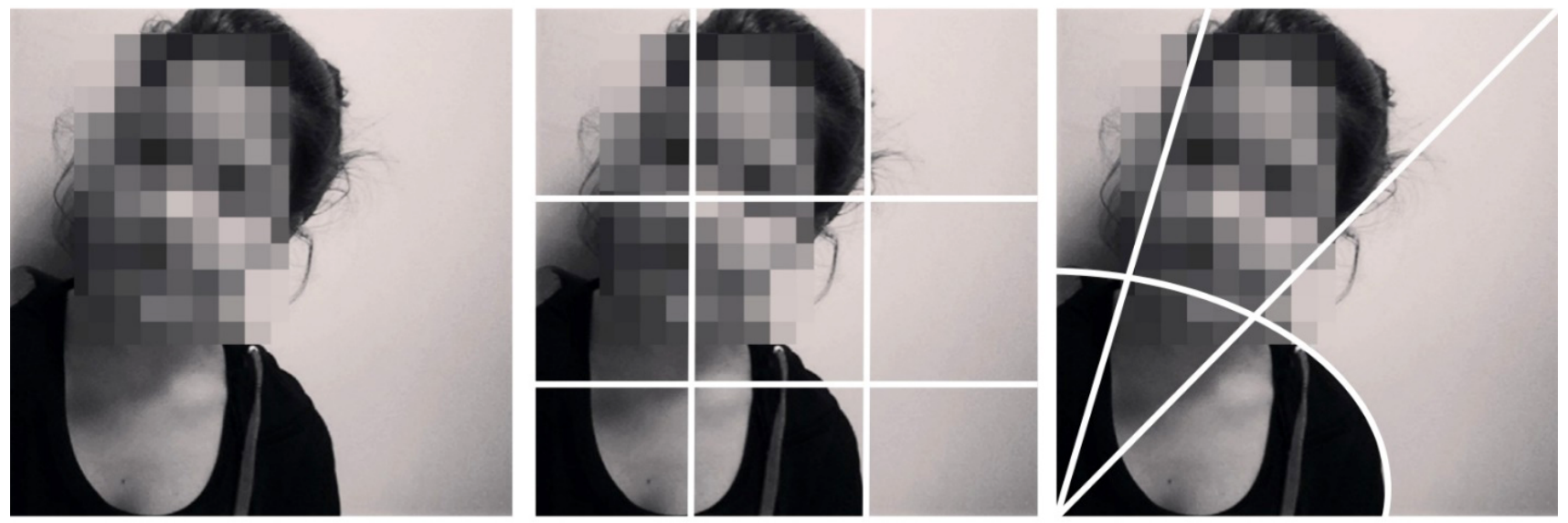

Figure 3. Compositional structure picture "Anna". 
with the quote and thereby enforces a specific layer of meaning, an ambiguity that is neither only positive nor negative, but part of her everyday life. Yet the comments do not really pick up this ambivalence and sponginess but rather focus on what the motif of the picture actually is: Anna, or even more so: Anna's body. The first comment refers to her appearance as "such a beauty" the second comment refers to her collarbone, ${ }^{5}$ which is emphasized in the picture by the composition/neckline of the shirt. Both commentators, therefore, thematise the shown body and introduce categories of attractiveness as relevant frames for body pictures. In thanking them for the comments, Anna again validates this framing.

\subsection{Example "Flora"}

Again, I will start with the visual analysis of the picture, which is visible in the screenshot (Figure 4).

Flora and her female dog are outside in the woods, at daylight in autumn or spring. The dog is well groomed, Flora is focused on producing a picture. She is in her 70s, but also well "groomed" and youthful. She smiles and looks at the camera, her hair is a bit dishevelled and her skin wrinkled with some age spots. Her clothes are functional but also colourful and chic. Woman and dog are on eye level and their bodies touch, the dog lies on a wooden panel, a bit behind Flora, she is sitting on something. The social situation the picture shows is a short break during a walk in the forest, nothing extraordinary like a holiday or a special occasion, rather a routine activity and the shared everyday - the woman and dog live together and spend their time and life together.

Compositionally, the woman and the dog are taking up a bit more than the lower half of the whole picture. Perspective and composition are merging in this picture, like in most selfies with two people or beings there is an $x$-shaped composition visible (see Figure 5), which emphasises the parallelity and equality of the pictured beings. They are on eyelevel in a practical and metaphorical sense, the dog is a bit more centred in the picture, but does not look at the viewer and is smaller than Flora, who leans backwards a little bit to fit into the picture with the dog.

In the picture, the closeness of the two is apparent; they are companions even though they are quite different. By emphasizing this togetherness, the picture also stresses that they are not alone. The dog is Flora's everyday companion and she places herself at eyelevel with him. This ambivalence of being together yet "only" with a dog, is visible in the picture.
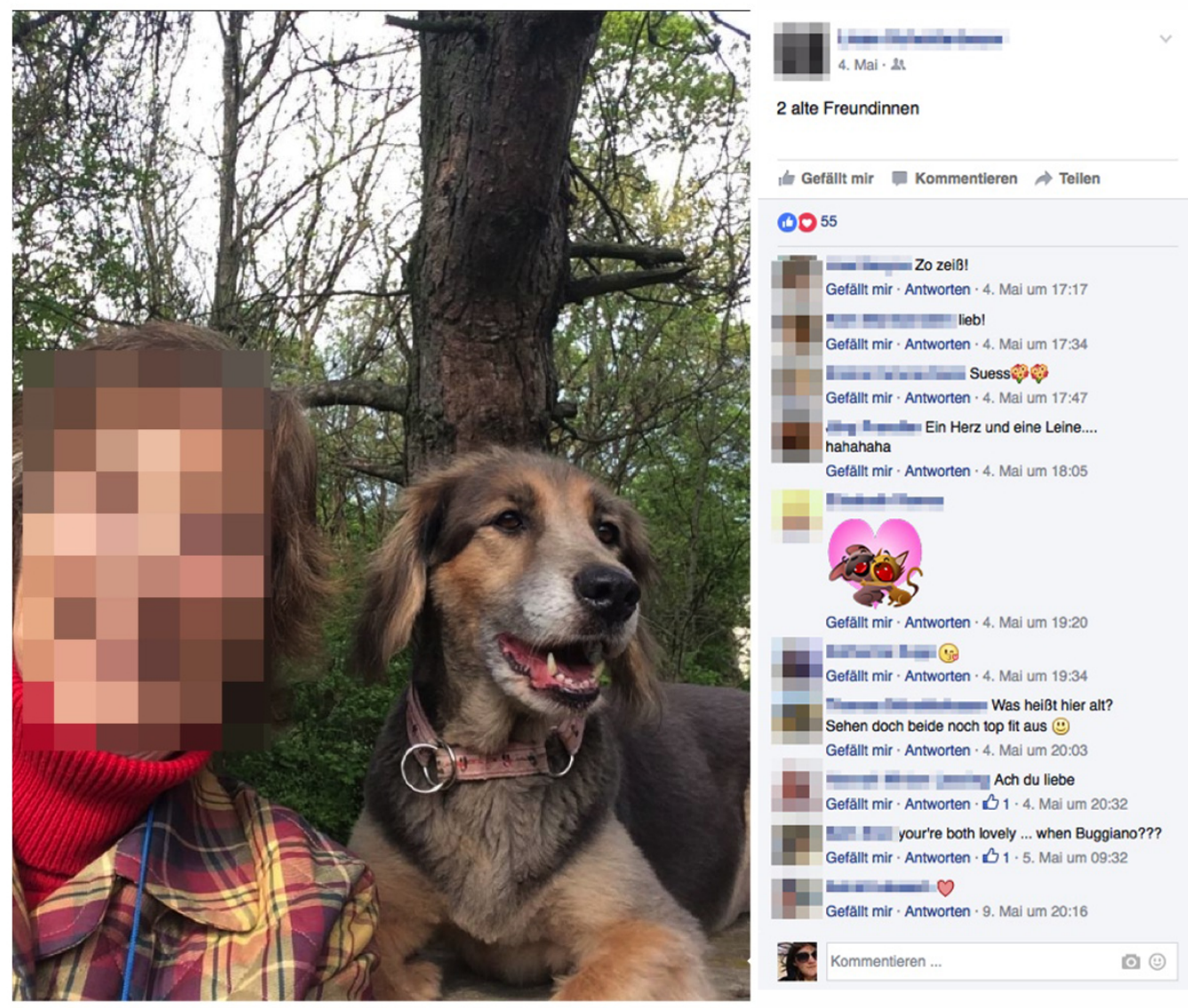

Figure 4. Screenshot of picture with caption and comments.

\footnotetext{
${ }^{5}$ As I know from the interview, Anna is very fond of collarbones, so it is quite probable that the commentator knows that too.
} 


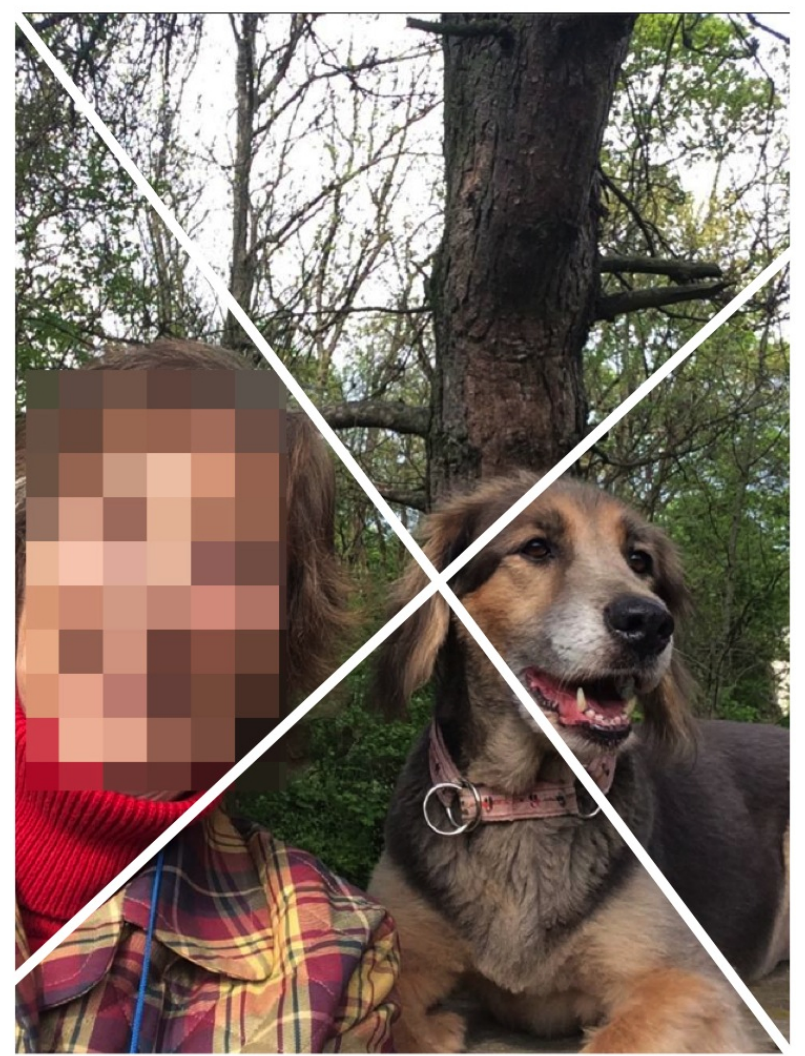

Figure 5. Compositional structure of picture, marked by author.

If we grasp the picture as the first expression in a communicative exchange, it shows a dissimilar yet equal couple, living their lives together. This first expression is framed by Flora through the caption, which further abstracts the relationship of the two pictured beings: "2 old friends" (German original: "2 alte Freundinnen", "Freundinnen" being the female plural form of "friends").

The way Flora frames the picture in her caption refers to an abstract motif, a general relationship, a state of being, what two old friends might look like. This caption invokes a rather distant perspective, a gaze from outside, an outer view. Ten comments were posted briefly after the upload (see Table 2). Some validated the pair in a loving way, some had a rather belittling tone to them.

Comment 5 is a visual comment: two animals who are hugging in a friendly manner (without eye contact or lips touching). This comment picks up aspects of the picture or the pictured, the embodied relationship in a comic animated way, the friendly closeness of the bodies and the furry animal.

Comment 7 refers to the topic of life age which Flora proposed, saying "both still looking topfit", which implies the possibility of not being fit and being old anymore at some point, and "still" rather emphasizing that it could be different. The parallelity of Flora and the dog is validated with "both", yet the comment sticks to the descriptive, distant outer view perspective, in formulating "both look" and not "you look". In contrast, commentators 8 and 9 address Flora or the couple directly and lovingly.

The equality of the beings which is visible in the picture is not validated by all commentators unanimously, for instance in comment 4: "A heart and a leash". In German, "Ein Herz und eine Seele" is a German figurative expression for two people being very close to each other, the exact translation would be "A heart and a soul", yet here the "soul" is substituted with "leash" as a metaphor for the dog. Therefore, it clearly thematises the inequality of a human owner and a dog who is leashed to his mistress. It implies that a dog might not really have a soul, but a leash and the human will always have more power. With the written expression of laughter ("hahahaha") the comment is framed with humour, yet also insecurity, irony, and maybe even provocation.

By and large, the pictured couple is validated as a couple, but the ambivalence in regard to age and parallelity that already shows in the picture continues in the comments.

Table 2. English translation of German comments which are visible in Figure 4.

\begin{tabular}{l}
\hline C1: So sweet! \\
\hline C2: lovely! \\
\hline C3: Cute (flower flower) \\
\hline C4: A heart and a leash .... hahahaha \\
\hline C5: (Emoji-see screenshot) \\
\hline C6: :-* \\
C7: What's that supposed to mean, old? They are both \\
still looking top fit. \\
\hline C8: Alas you lovely \\
\hline C9: you're both lovely ... when Buggiano??? \\
C10: <3
\end{tabular}

\subsection{Platform Analysis}

Based on screenshots and mappings of the upload processes, patterns of sharing cultures can be reconstructed. ${ }^{6}$ Anna has shared her picture on Instagram, Flora hers on Facebook. Both platforms, Instagram and Facebook, have a similar basic structure: Users need an account to be part of the network and to follow the posts of others. User pages are structured chronologically, with the latest post on top. Facebook enforces a rather biographical narrative (Van Dijck, 2013b), while Instagram pushes forward a consistent aesthetic and networking through hashtags (Highfield \& Leaver, 2016). While Facebook also remediates an album-structure regarding pictures (Walser \& Neumann-Braun, 2013), Instagram enforces a logic of pictures as a "data stream" (Hochman, 2014). However, while on Instagram visual

\footnotetext{
${ }^{6}$ The platform analyses are elaborated in more detail in Schreiber (in press, 2017).
} 
data is the main content of every post, on Facebook all kinds of data can be shared and also traces of other interactions with people or sites become visible (for example: Maria likes Anna's picture, Maria is interested in event X).

Regarding picture sharing, both platforms make pictures visible publicly or to all friends by default. Choosing a specific audience is not part of the default upload process in Instagram and Facebook (contrary to WhatsApp or Snapchat) and has to be done additionally. Following this logic, Villi differentiated between two modes of visual communication, publishing and messaging. The postings above are posted in semi-public "publishing" contexts, which may replicate earlier forms of presentation, such as "the act of placing the photograph on a pedestal in a crowded room....The others may or may not view the photograph, and if they do view it, they will not necessarily do so immediately" (Villi, 2015, p. 10). In contrast, visual messaging practices are rather reciprocal and often take place in real-time and within intimate spheres which are not easily accessible to researchers. Compared to apps like WhatsApp and Snapchat, Facebook's and Instagram's technical structures and interfaces push forward sharing practices aimed at a more loosely defined intimate audience.

\subsection{Comparative Analysis and Findings Regarding the Examples}

In this section, the practices of collaborative meaningmaking that have been reconstructed in the two examples will be compared and related to the interface structure of the platforms to answer the research question: how does collaborative meaning-making of visual media take place on social media platforms?

In both cases, the picture is a first (visual) statement in communicative interactions. Both pictures have been selected and authorised by Anna and Flora for their accounts. Both pictures convey layers of meaning that can be elaborated and further framed in visual or textual communication. Moreover, both pictures are selfies, a genre that is intrinsically linked to sharing and visibility politics of social media (Tiidenberg \& Gómez-Cruz, 2015). While Anna and Flora are at very different stages in their lives, they both show and share their portraits and thereby themselves in the networked environments where they put them up for discussion. Anna's adolescent body and Flora's ageing body are collaboratively negotiated through comments and reactions such as likes and GIFs.

Platforms are co-constituting this practice and the emerging genre, because they afford the technical possibilities of sharing, liking and commenting. They push forward visual communication as "visual chat" (GómezCruz \& Thornham, 2015, p. 6) and afford a variety of possibilities for commenting, such as through emojis. Yet interaction is not only promoted on the technical but also on the visual level: The portrait as an iconographic genre offers the picture of a face as inter-face to the viewer, enabling a possibility to communicate with the portrait as a placeholder for the pictured person (Belting, 2013, p. 136). As the comments in the examples show, different interpretations and references may exist alongside each other. Likes and comments are well-rehearsed elements in both platforms, they give users the ability to show that they have seen the picture and to acknowledge a mediated presence in a specific social media context, no matter where they are and when they see the picture; these abilities were made use of in both cases.

Regarding the platforms, both Facebook and Instagram quickly expanded and refined the possibilities of liking and commenting since the original collection of the discussed examples in 2014 and 2015: Facebook added more possibilities to react to postings besides the thumbup like-symbol, both platforms implemented a forumlike structure that made it possible to comment on comments, the range of emojis, stickers, and reaction gifs grew, and linking other users in comments became easily possible. These technical developments indicate that collaborative meaning-making is a key practice of (visual) communication, how such collaborative meaningmaking is enhanced by the design and logic of social media should be investigated further.

\section{Conclusions}

The dissection of three levels of analyses has been helpful to make the complex interrelations of visual communication and social media more transparent, easier to reconstruct and analyse. Visual conventions, aesthetics, interfaces and defaults are inscribed in, and entangled with, practices of collaborative meaning-making in our everyday lives. A picture shared on social media is a first visual step within a multimodal conversation or interaction, an initial proposition of certain layers of meaning, which is further negotiated, framed and elaborated on by subsequent communicative expressions. These expressions can have many forms, they might be linguistic, visual or multimodal. These expressions could then be affirmative, oppositional, sceptical etc. in relation to the initial visual proposition.

By commenting on a picture, users participate in a process of collaborative meaning-making of and around the picture. The underlying chronological structure of Facebook's timeline and Instagram's feed or account allows users to show change and development but also to curate their account, for example by deleting pictures that do not "fit" anymore. Platforms clearly make these practices more accessible and potentially more reflexive, they stimulate continuous status updates and put forth the processuality of doing identity and sociality as a dynamic practice rather than a fixed entity-a conclusion others have also arrived at (Klinger \& Svensson, 2015; Marwick, 2013; Meikle, 2016; Whitlock \& Poletti, 2008).

However, this contribution (and this thematic issue) is specifically interested in the visual dimension of this transformation. What might be specific to meaningmaking regarding visual communication on social media? 
Firstly, comments mainly refer to visible bodies and aesthetics. While this might seem mundane, it has to be recognised that visual media are especially adequate/fit to show embodied, aesthetic and affective meanings which might be hard to put into words and text (Bal, 2003; Rose, 2014). This is also clearly visible in the development of reaction GIFs, ${ }^{7}$ which seem to endlessly extend and culturally refine the repertoire of visual emotional expressions that emojis have offered. Visual social media reminds us time and again that facial and embodied expressions remain crucial as "social cues" (Baym, 2015) in digital, networked communication; they seem to have pushed forward a re-embodiment, a return of flesh and bone to social media.

Secondly, photographic pictures, and probably visual media in general, seem to be ideal for showing ambiguous, multiple or disputed layers of meaning, as also identities can be rather ambiguous and multiple (Goffman, 1959; Marwick, 2013). One can be child and woman at the same time, like Anna-or be alone and not alone at the same time, like Flora. Unlike text, which is a sequential medium, pictures convey meaning in a simultaneous manner and therefore allow us to show different layers and aesthetics at the same time.

The proposed framework is primarily suitable for qualitative, in-depth case studies where contextual information regarding the pictures and sharing practices is available. Moreover, a screenshot is a snapshot in time, and for research investigating individual dynamic developments and changes, longitudinal analyses would be pivotal. Also, the framework would have to be adapted to accommodate a larger corpus of data. The analysis of static, photographic pictures can be grounded in a considerable corpus of existing (methodologic) scholarship; however, formats such as reaction GIFs, memes, stories etc., which are quite new developments also challenge visual methods further and should be investigated.

\section{Acknowledgments}

The author wants to thank the anonymous reviewers and the editors of the thematic issue for their helpful comments on an earlier draft of this article. This research has been funded by the Austrian Academy of Sciences (ÖAW). Open access funding provided by the University of Vienna. Funding for language editing services provided by by the Faculty of Social Sciences at the University of Vienna.

\section{Conflict of Interests}

The author declares no conflict of interests.

\section{References}

Abidin, C. (2016). Visibility labour: Engaging with Influencers' fashion brands and \#OOTD advertorial cam- paigns on Instagram. Media International Australia, 161(1), 86-100.

Ardèvol, E., \& Gómez-Cruz, E. (2013). Digital ethnography and media. In F. Darling-Wolf (Ed.), The international encyclopedia of media studies: Research methods in media studies (pp. 498-518). Hoboken, NJ: WileyBlackwell.

Bal, M. (2003). Visual essentialism and the object of visual culture. Journal of Visual Culture, 2(1), 5-32.

Barad, K. (2003). Posthumanist performativity: Toward an understanding of how matter comes to matter. Signs: Journal of Women in Culture and Society, 28(3), 801-831. doi:10.1086/345321

Barad, K. (2007). Meeting the universe halfway. Quantum physics and the entanglement of matter and meaning. Durham, NC: Duke University Press.

Baym, N. K. (2009). What constitutes quality in qualitative internet research? In A. N. Markham \& N. K. Baym (Eds.), Internet inquiry (pp. 173-189). London: SAGE.

Baym, N. K. (2015). Personal connections in the digital age (2nd ed.). Cambridge: Polity Press.

Belting, H. (2013). Faces; eine Geschichte des Gesichts [A history of the face]. Munich: Beck.

Bohnsack, R. (2008, September 28). The interpretation of pictures and the documentary method. Forum Qualitative Sozialforschung/Forum: Qualitative Social Research. Retrieved from http://www.qualitativeresearch.net/index.php/fqs/article/view/1171/2591

Bohnsack, R. (2014). Documentary method. In U. Flick (Ed.), The SAGE handbook of qualitative data analysis (pp. 217-233). London: SAGE.

Bourdieu, P. (1972). Outline of theory of a theory of practice. Cambridge: Cambridge University Press.

Bourdieu, P., Boltanski, L., Castel, R., Chamboredon, J.-C., Schnapper, D., \& Whiteside, S. (1990). Photography: A middle-brow art. Cambridge: Polity Press.

boyd, d. (2011). Social network sites as networked publics. In Z. Papacharissi (Ed.), A networked self. Identity, community, and culture on social network sites (pp. 39-58). New York, NY: Routledge.

boyd, d., \& Crawford, K. (2012). Critical questions for big data. Information, Communication \& Society, 15(5), 662-679.

Bräuchler, B., \& Postill, J. (2010). Theorising media and practice. New York, NY: Berghahn.

Brown, B. (2010). Materiality. In W. Mitchell \& M. B. Hansen (Eds.), Critical terms for media studies (pp. 49-63). Chicago, IL: The University of Chicago Press.

Bucher, T., \& Helmond, A. (in press). The affordances of social media platforms. In J. Burgess, T. Poell, \& A. Marwick (Eds.), The SAGE handbook of social media. London: SAGE.

Burri, R. V. (2012). Visual rationalities: Towards a sociology of images. Current Sociology, 60(1), 45-60.

Couldry, N. (2004). Theorising media as practice. Social Semiotics, 14(2), 115-132.

\footnotetext{
${ }^{7}$ The platform analyses are elaborated in more detail in Schreiber (in press, 2017).
} 
Couldry, N., \& Van Dijck, J. (2015). Researching social media as if the social mattered. Social Media + Society, 1(2), 1-7.

Degen, M., Melhuish, C., \& Rose, G. (2017). Producing place atmospheres digitally: Architecture, digital visualisation practices and the experience economy. Journal of Consumer Culture, 17(1), 3-24.

Gershon, I. (2010). Breaking up is hard to do: Media switching and media ideologies. Linguistic Anthropology, 20(2), 389-405.

Gillespie, T. (2013). The politics of "platforms". In J. Harley, J. Burgess, \& A. Bruns (Eds.), A companion to new media dynamics (pp. 407-416). Oxford: WileyBlackwell.

Goffman, E. (1959). The presentation of self in everyday life. New York, NY: Doubleday.

Goffman, E. (1987). Gender advertisements. New York, NY: Harper Torchbooks.

Gómez-Cruz, E., \& Thornham, H. (2015). Selfies beyond self-representation: The (theoretical) $f(r)$ ictions of a practice. Journal of Aesthetics \& Culture, 7, 1-10.

Grace, H. (2014). Culture, aesthetics and affect in ubiquitous media; the prosaic image (1st ed.). London: Routledge.

Hand, M. (2012). Ubiquitous photography. Cambridge: Polity Press.

Hasebrink, U., \& Hepp, A. (2017). How to research crossmedia practices? Investigating media repertoires and media ensembles. Convergence: The International Journal of Research into New Media Technologies, 23(4), 362-377.

Highfield, T., \& Leaver, T. (2016). Instagrammatics and digital methods: Studying visual social media , from selfies and GIFs to memes and emoji. Communication Research and Practice, 2(1), 47-62.

Hine, C. (2015). Ethnography for the Internet. Embedded, embodied and everyday. London: Bloomsbury.

Hirschauer, S. (2008). Die Empiriegeladenheit von Theorien und der Erfindungsreichtum der Praxis [Theory's empirical grounding and the inventiveness of practice]. In H. Kalthoff, S. Hirschauer, \& G. Lindemann (Eds.), Theoretische Empirie. Zur Relevanz qualitativer Forschung [Theoretical empiricism. On the relevance of qualitative research] (pp. 165-187). Frankfurt am Main: suhrkamp.

Hjorth, L., \& Lim, S. S. (2012). Mobile intimacy in an age of affective mobile media. Feminist Media Studies, 12(4), 477-484.

Hochman, N. (2014). The social media image. Big Data \& Society, 1(2), 1-15.

Hörnig, K., \& Reuter, J. (2004). Doing culture: Kultur als Praxis. In K. Hörnig \& J. Reuter (Eds.), Doing Culture. Neue Positionen zum Verhältnis von Kultur und sozialer Praxis [New perspectives on the relation of culture and social practice] (pp. 9-15). Bielefeld: transcript.

Hutchby, I. (2001). Technologies, texts and affordances. Sociology, 35(2), 441-456. doi:10.1177/

\section{S0038038501000219}

Hutchby, I. (2014). Communicative affordances and participation frameworks in mediated interaction. Journal of Pragmatics, 72, 86-89.

Imdahl, M. (1994). Ikonik. Bilder und ihre Anschauung [The iconic. Pictures and their perception]. In G. Boehm (Ed.), Was ist ein Bild? [What is a picture?] (pp. 300-324). Munich: Wilhelm Fink.

Keightley, E., \& Pickering, M. (2014). Technologies of memory: Practices of remembering in analogue and digital photography. New Media \& Society, 16(4), 576-593.

Klinger, U., \& Svensson, J. (2015). The emergence of network media logic in political communication: A theoretical approach. New Media \& Society, 17(8), 1241-1257.

Latour, B. (1991). Technology is society made durable. In J. Law (Ed.), A sociology of monsters essays on power, technology and domination. London: Routledge.

Leaning, M. (2009). The Internet, power and society. Oxford: Chandos Publishing.

Lehmuskallio, A., \& Gómez-Cruz, E. (2016). Why material visual practices? In E. Gómez Cruz \& A. Lehmuskallio (Eds.), Digital photography and everyday life. Empirical studies on material visual practices (pp. 1-16). London: Routledge.

Light, B., Burgess, J., \& Duguay, S. (2016). The walkthrough method: An approach to the study of apps. New Media \& Society. doi:10.1177/ 1461444816675438

Madianou, M., \& Miller, D. (2012). Polymedia: Towards a new theory of digital media in interpersonal communication. International Journal of Cultural Studies, 16(2), 169-187.

Mahrt, M., \& Scharkow, M. (2013). The value of big data in digital media research. Journal of Broadcasting \& Electronic Media, 57(1), 20-33.

Mannheim, K. (1998). The sociological problem of generations. In K. Mannheim (Ed.), Essays on the sociology of knowledge (pp. 163-195). London: Taylor \& Francis Books UK.

Markham, A. (2004). The Internet as research context. In C. Seale, J. Gubrium, D. Silverman, \& G. Gobo (Eds.), Qualitative research practice (pp. 358-374). London: SAGE.

Markham, A. (2012). Fabrication as ethical practice: Qualitative inquiry in ambiguous Internet contexts. Information, Communication \& Society, 15(3), 334-353.

Markham, A. (2013). Remix cultures, remix methods. Reframing qualitative inquiry for social media contexts. In N. K. Denzin \& M. D. Giradina (Eds.), Global dimensions of qualitative inquiry (pp. 63-81). Walnut Creek, CA: Left Coast Press.

Markham, A., \& Baym, N. K. (2009). Internet inquiry; conversations about method. Los Angeles, CA: SAGE.

Markham, A., \& Buchanan, E. (2015). Internet research: Ethical concerns. In J. Wright (Ed.), International encyclopedia of the social \& behavioural sciences (pp. 
606-613). Amsterdam: Elsevier.

Marwick, A. E. (2013). Online identity. In J. Hartley, J. Burgess, \& A. Bruns (Eds.), A companion to new media dynamics (pp. 355-364). Oxford: Wiley-Blackwell.

Marwick, A. E., \& boyd, d. (2011). I tweet honestly, I tweet passionately: Twitter users, context collapse, and the imagined audience. New Media \& Society, 13(1), 114-133.

McVeigh-Schultz, J., \& Baym, N. K. (2015). Thinking of you: Vernacular affordance in the context of the microsocial relationship app, couple. Social Media + Society, 1(2), 1-13.

Mead, G. H. (1967). Mind, self and society from the standpoint of a social behaviorist. Edited with an introduction by Charles W. Morris. Chicago, IL: University of Chicago Press.

Meikle, G. (2016). Social media; communication, sharing and visibility. London: Routledge.

Müller, M. R. (2011). Das Körperbild als Selbstbild [The body-image as self-image]. In M. R. Müller, H.-G. Soeffner, \& A. Sonnenmoser (Eds.), Körper Haben. Die symbolische Formung der Person [Having dody. The symbolic shaping of the person] (pp. 87-106). Weilerswist: Velbrück.

Pink, S., Horst, H., Postill, J., Hjorth, L., Lewis, T., \& Tacchi, J. (2015). Ethnography in a digital world. In S. Pink, H. Horst, J. Postill, L. Hjorth, T. Lewis, \& J. Tacchi (Eds.), Digital ethnography. Principles and practice (pp. 1-18). London: SAGE.

Przyborski, A. (2017). Bildkommunikation. Qualitative Bild- und Medienforschung [Iconic communication. Qualitative research on pictures and Media]. Oldenbourg: De Gruyter.

Przyborski, A., \& Slunecko, T. (2012). Learning to think iconically in the human and social sciences: Iconic standards of understanding as a pivotal challenge for method development. Integrative Psychological and Behavioral Science, 46(1), 39-56.

Reckwitz, A. (2002). Toward a theory of social practices: A development in culturalist theorizing. European Journal of Social Theory, 5(2), 243-263.

Rose, G. (2012). Visual methodologies: An introduction to researching with visual materials (3rd ed.). London: SAGE Publications.

Rose, G. (2014). On the relation between "visual research methods" and contemporary visual culture. The Sociological Review, 62(1), 24-46.

Russmann, U., \& Svensson, J. (2017). Introduction to visual communication in the age of social media: Conceptual, theoretical and methodological challenges. Media and Communication, 5(4), 1-5.

Sarvas, R., \& Frohlich, D. M. (2011). From snapshots to social media; the changing picture of domestic photography. London: Springer.

Schade, S., \& Wenk, S. (2011). Studien zur visuellen Kultur. Einführung in ein transdisziplinäres Forschungsfeld [Studies on visual culture. Introduction to a transdisciplinary field of research]. Bielefeld: transcript.
Schirmer, D., Sander, N., \& Wenninger, A. (2015). Die qualitative Analyse internetbasierter Daten; Methodische Herausforderungen und Potenziale von Online-Medien [The qualitative analysis of internetbased data; Methodical challenges and potentials of online media]. Wiesbaden: Springer Fachmedien Wiesbaden.

Schmidt, J.-H. (2013). Practices of networked identity. In In J. Harley, J. Burgess, \& A. Bruns (Eds.), A companion to new media dynamics (pp. 365-374). Oxford: WileyBlackwell.

Schmidt, R. (2012). Soziologie der Praktiken. Konzeptionelle Studien und empirische Analysen [Sociology of practices. Conceptual and empirical studies]. Frankfurt am Main: suhrkamp.

Schreiber, M. (in press). Audiences, aesthetics and affordances: Analysing practices of visual communication on social media. Digital Culture \& Society, 3(2).

Schreiber, M. (2017). Digitale Bildpraktiken. Handlungsdimensionen visueller vernetzter Kommunikation [Digital picture practices. Dimensions of visual networked communication] (Unpublished Doctoral thesis). University of Vienna, Vienna, Austria.

Schreiber, M., \& Kramer, M. (2016). Verdammt schön. Methodologische und methodische Herausforderungen der Rekonstruktion von Bildpraktiken auf Instagram [Damn beautiful. Methodological and methodical challenges of reconstructing pictorial practices on Instagram]. Zeitschrift Für Qualitative Sozialforschung, 17(1/2), 81-106.

Senft, T. M., \& Baym, N. K. (2015). What does the selfie say? Investigating a global phenomenon introduction. International Journal of Communication, 9, 1588-1606.

Thiel-Stern, S. (2012). Collaborative, productive, performative, templated: Youth, identity and breaking the fourth wall. In R. A. Lind (Ed.), Produsing theory in a digital world (pp. 87-103). New York, NY: Peter Lang

Tiidenberg, K., \& Gómez-Cruz, E. (2015). Sefies, image and the re-making of the body. Body \& Society, 21(4), 77-102.

Tinkler, P. (2013). Using photographs in social and historical research. London: SAGE Publications.

Van Dijck, J. (2007). Mediated memories in the digital age. Stanford, CA: Stanford University Press.

Van Dijck, J. (2013a). The culture of connectivity: A critical history of social media. Oxford: Oxford University Press.

Van Dijck, J. (2013b). "You have one identity": Performing the self on Facebook and LinkedIn. Media, Culture \& Society, 35, 199-215.

Van Dijck, J., \& Poell, T. (2013). Understanding social media logic. Media and Communication, 1(1), 2-14.

Villi, M. (2015). "Hey, I'm here right now": Camera phone photographs and mediated presence. Photographies, 8(1), 3-22.

Walser, R., \& Neumann-Braun, K. (2013). Freundschaftsnetzwerke und die Welt ihrer Fotoalben-gestern 
und heute. In C. Wijnen, S. Trültzsch, \& C. Ortner (Eds.), Medienwelten im Wandel SE-12 (pp. 151166). Wiesbaden: Springer.

Whitlock, G., \& Poletti, A. (2008). Self-regarding art. Biography, 31(1), V-XXXIII.

Zillien, N. (2008). Die (Wieder-)Entdeckung der Medien.
Das Affordanzkonzept in der Mediensoziologie [The (re-)discovery of media. The concept of affordances in media sociology]. Sociologia Internationalis : Internationale Zeitschrift Für Soziologie, KommunikationsUnd Kulturforschung, 46(2), 161-181.

\section{About the Author}

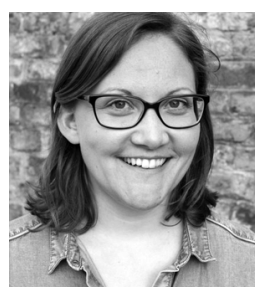

Maria Schreiber (PhD in Media and Communication Studies, University of Vienna) has been a visiting PhD student at the doctoral school "Visibility and Visualisation" within the University of Potsdam, Germany, as well as at the Digital Ethnography Research Center at RMIT University, Melbourne, Australia. Maria is a post-doctoral researcher in the project "VIS_BIO. Visual biographies in networked lifeworlds" at the Department of Sociology within the University of Vienna. 